\title{
Diálogos y relaciones de poder en los albores del reino visigodo hispano: el reinado de Amalarico (5II-53I)
}

\author{
Pablo Poveda Arias \\ ROMANISLAM \\ Center for Comparative Empire \\ and Transcultural Studies \\ UniversitäT HambUrg \\ Dialogues and Relationships of Power \\ at the Dawn Visigothic Kingdom in Iberia: \\ The Reign of Amalaric (511-531)
}

Pablo.Poveda.Arias@uni-hamburg.de.

El presente estudio ha sido desarrollado en el marco de un proyecto de

investigación postdoctoral financiado por la Fritz Thyssen Stiftung

(Ref. 49.19.0.0I4GE) y del proyecto

de investigación HAR2016-76094,

financiado por el Ministerio

de Ciencia e Innovación.

RECIBIDO: II-O2-2020

EVALUADO Y ACEPTADO: 3I-03-2020

Territorio, Sociedad y Poder, No I5, 2020 [PP. 9-23] 
Resumen: La derrota de los visigodos en la batalla de Vouillé (507) supuso un punto de inflexión en el desarrollo político del reino visigodo, haciéndose notar sus consecuencias durante toda la primera etapa del nuevo regnum que nació en Hispania precisamente a raíz de este fracaso militar. Con el objetivo de poder entender la nueva situación, el trabajo que aquí presentamos pretende ilustrar las dinámicas de poder vigentes en este período germinal del reino visigodo hispano a través del caso del reinado de Amalarico (511-531). El estudio propuesto ofrecerá una lectura

Aвstract: The defeat of the Visigoths at the Battle of Vouillé (507) was a turning point in the political development of the Visigothic kingdom, and its consequences were felt throughout the first stage of the new regnum that was born in Hispania precisely as a result of this setback. In order to understand the new situation after, the work presented here aims to illustrate the power dynamics in force during this germinal period of the Visigothic kingdom in Hispania through the case of the reign of Amalaric (511-531). The proposed study alejada de la perspectiva teleológica y los análisis excesivamente negativos que transmiten las fuentes y determinados sectores de la historiografía moderna en lo referido a este período y a la propia figura de Amalarico. El perfil que presentaremos del mismo pondrá de relieve, por el contrario, el pragmatismo de este monarca a la hora de hacer frente a las distintas amenazas internas que marcaron su reinado.

Palabras Clave: Competencia; Dinámicas de Poder; Montano de Toledo; Obispos; Teodorico.

will offer a reading far from the teleological perspective and the excessively negative analyses that the sources and certain sectors of modern historiography transmit with regard to this period and the very figure of Amalaric. On the contrary, the profile that we will present of him will highlight the pragmatism of this king when facing the different internal threats that marked his reign.

Keywords: Bishops; Competition; Dynamics of Power; Montanus of Toledo; Theodoric. 


\section{INTRODUCCIÓN}

La dura derrota sufrida en el año 507 por los visigodos a manos del rey merovingio Clodoveo en el campo de Vouillé trajo consigo la pérdida de la mayor de las posesiones godas en la Galia y el obligado repliegue de los visigodos a Hispania. ${ }^{1}$ A esto se le suma la situación de precariedad política en la que se sumió la propia monarquía, primero por la muerte en batalla de Alarico II y, a continuación, por la posición de debilidad de sus nuevos titulares, quienes de forma mayoritaria acabaron sus días de forma violenta, ${ }^{2}$ una situación en

\footnotetext{
${ }^{1}$ Chron. Gall. a. 5II, 86 [688]: «Occisus Alaricus rex Gothorum a Francis». Ed. Burgess, 200I: 99; Chron. Caesar. (a. 507), 88a, 467-469: «His diebus pugna Gotthorum cum Francorum Boglada facta. Alaricus rex in proelio a Francis interfectus est: regnum Tolosanum destructum est». Ed. Cardelle

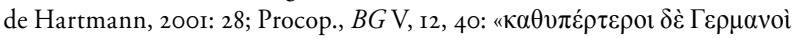

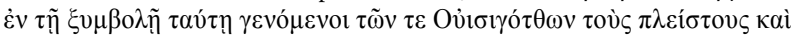

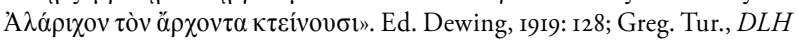
II, 37. Ed. Krusch, Levison, I95I: 85-88, esp. 87-88; Isid. Hisp., Hist. 36, red. breve, 5-II: «Qui cum a pueritia uitam in otio et conuiuio peregisset, tandem prouocatus a Francis in regione Pictauensis urbis proelio inito extinguitur eoque interfecto regnum Tolosanum occupantibus Francis destruitur»; red. larga, 5-II: «Aduersus quem Fluduicus Francorum princeps Galliae regnum affectans Burgundionibus sibi auxiliantibus bellum mouit fusisque Gothorum copiis ipsum postremo regem apud Pictauis superatum interfecit». Ed. Rodríguez Alonso, 1975: 230. Sobre las circunstancias de esta derrota, véase Valverde Castro, 2002.

2 Ilustrando tales ideas: DLH III, 30, 9-II: «Sumpserant enim Gothi hanc detestabilem consuetudinem, ut, si qui seis de regibus non placuisset, gladio eum adpeterent, et qui libuisset animo, hunc sibi statuerent regem»; Fredeg., Chron. III, 42: "Gothi uero iam olim habent uicum, cum rex eis non placeat ab ipsis interficetur». Ed. Desgrugillers, 2OII: I48; IV, 82, IO-II: «[...] cognetus morbum Gotorum quem de regebus degradandum habebant [...]». Ed. Devillers, Meyers, 200I: I84.
}

lo que sin duda incidió la propia fragmentación y desunión de las élites visigodas (Wood, 20I2a: 39-40). El objetivo del presente trabajo es ilustrar las dinámicas de poder desarrolladas en estos contextos germinales del reino visigodo hispano, empleando para ello el caso del reinado de Amalarico (5II-53I). Dicho estudio, sin embargo, entrańa ciertas dificultades, dada la escasez de testimonios que tratan el período en cuestión, el menos en comparación con aquellos referidos a momentos más avanzados. Al carácter lacónico de las fuentes se le suma, salvo excepciones, su naturaleza tardía, con autores que distaron incluso varias generaciones de los hechos narrados, como ocurrió con Gregorio de Tours o Isidoro de Sevilla. Esta última circunstancia hace que muchos de los avatares políticos de este reinado sean bastante confusos, con contradicciones patentes en algunos casos. Asimismo, la distancia temporal también hizo de este reinado un campo propicio sobre el que proyectar juicios de valor negativos y teleológicos, una imagen en la que sin duda incidió su condición de monarca derrotado frente a los francos. ${ }^{3}$ Es cierto que en ello también influyeron los propios prejuicios de los distintos autores. Tal y como tendremos ocasión de

\footnotetext{
3 Véase infra. Las derrotas militares siempre influyeron en la construcción posterior de la imagen de un monarca determinado. Así se pone en evidencia también en Isid. Hisp., Hist. 58, red. larga, I-6: «Aera DCXLI, anno imperii Maurici XX extincto Liuuane Wittericus regnum, quod uiente illo inuaserat, uindicat annis VII, uir quidem sirenuus in armorum arte, sed tamen expers uictoriae». Véase Pohl, Dörler, 2015: 136.
} 
comprobar, estos influyeron sustancialmente cuando entraban en juego factores religiosos, una cuestión que contribuyó, a nuestros ojos, a la construcción de una imagen distorsionada de este monarca, al menos si lo comparamos con otras noticias. ${ }^{4}$

A esta situación ya de por sí desconsoladora se le suma el desinterés que la historiografía ha mostrado hacia la figura de Amalarico, eclipsado por reyes más exitosos como Teudis, Leovigildo o Recaredo. Prueba de ello es la ausencia de trabajos monográficos dedicados a él frente a otros monarcas como los citados, que sí cuentan con estudios consagrados en exclusiva a sus reinados (Fuentes Hinojo, 1996; García Moreno, 2008; Castellanos, 2007). En general, debemos extraer las distintas lecturas referidas a este reinado de trabajos generales o de otros estudios que abordan de forma colateral la actuación de Amalarico. ${ }^{5}$ A esto se le suma la infravaloración que suele hacerse de esta figura desde historiografía moderna, una cuestión motivada sobre todo por las lecturas excesivamente confiadas que se han hecho de las fuentes disponibles. ${ }^{6}$

Frente a este panorama, nuestro propósito a lo largo de las siguientes páginas será presentar un retrato alternativo de la figura de Amalarico, poniendo de relieve, no solo sus notables sombras, sino también sus luces, cuya existencia queremos reivindicar en este trabajo. Para ello proponemos una interpretación de las fuentes alejada de la literalidad y de las lecturas teleológicas. De este modo, el cuestionamiento de los datos disponibles, su crítica exhaustiva y su comparación con el conjunto de evidencias disponibles primarán en nuestro análisis, el cual articularemos en torno a las dinámicas de poder vigentes durante el reinado de Amalarico. En concreto, nos centraremos en las distintas relaciones de poder que condicionaron el balance de fuerzas concurrentes, tanto entre agentes seculares como eclesiásticos.

\footnotetext{
${ }^{4}$ En torno a la problemática subyacente a las fuentes de este período, véase McKitterick, 1995; Halsall, 2005.

${ }^{5}$ Véase, por ejemplo, Orlandis, 1977; García Moreno, 1989; Díaz, Martínez Maza, Sanz Huesma, 2007.

${ }^{6}$ A modo de ejemplo: Wolfram, I988 [1979]: 310; Thompson, 20II [1969]: 24-26.
}

\section{LA DEBILIDAD DE AMALARICO FRENTE A LA ARISTOCRACIA SECULAR: EL DETERMINISMO DE LA REGENCIA}

Amalarico accedió al trono siendo aún un niño, sustituyendo a su medio hermano Gesaleico (507-51I). Este último, quien accedió al trono de los visigodos después de la muerte en Vouillé de su padre Alarico II, ${ }^{7}$ se trató ciertamente de un monarca de débil carácter, carente de las habilidades políticas y militares necesarias para mantenerse en el trono. Todo ello, además, en un contexto en el cual los visigodos sufrieron la mayor derrota sufrida hasta ese momento y que, en consecuencia, exigía un gobernante hábil y capaz, si no de recuperar posiciones, al menos de contener al enemigo franco; un perfil que presumiblemente Gesaleico distaba mucho de cumplir. En el ámbito estrictamente militar, fue derrotado en su primer choque con los merovingios, lo que forzó su repliegue de Narbona a Barcelona. ${ }^{8}$ Por otro lado, en la esfera política, este monarca se vio incapaz de mantener unidos a los visigodos en torno a su liderazgo. Así lo evidencian la ejecución de, presumiblemente, dos opositores a su gobierno, Goerico y Veila. ${ }^{9}$ Ante este panorama, y aprovechándose del carácter débil de Gesaleico, Teodorico el ostrogodo intervino para promocionar al trono visigodo a su nieto Amalarico, un movimiento que legitimó en su condición de hijo legítimo de Alarico II y Teodegonda, hija bastarda del ostrogodo, frente al carácter ilegítimo de Gesaleico. Para lograrlo, y a sabiendas de las escasas habilidades militares de este último, el rey ostrogodo

\footnotetext{
${ }^{7}$ Chron. Caesar. (a. 508), 89a, 476-477: «Post Alaricum Gisalecus rex ex concubina eius filius Gotthorum rex efficitur, regnat an. VII»; Procop., $B G$ V, I2, 43-44: «Ov̉ı

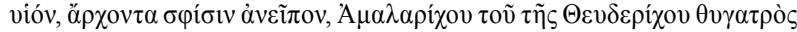

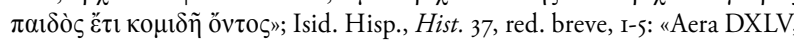
anno XVII Anastasii imperatoris Geselecus superioris regis ex concubina filius Narbonae princeps efficitus et regnauit annis quattuor». Sobre su reinado, véase Jiménez Sánchez, 2013.

${ }^{8}$ Isid. Hisp., Hist. 37, red. breve, 5-II: «[...] sicut genere utilissimus, ita infelicitate et ignauia summus. Denique dum eadem ciuitas a Gundebaldo Burgundionum rege direpta fuisset, iste cum multo sui dedecore et cum magna suorum clade apud Barcinonam se contulit». Ed. C. Rodríguez Alonso, p. 232.

${ }^{9}$ Chron. Caesar. (a. 510), 9Ia, 492-493: «His consulibus Gesalecus Goericum Barcinone in palatio interfecit [...]»; 92a, 50I: «Comes uero Veila Barcinone occiditur». Véase Jiménez Sánchez, 2013: 348-349.
} 
envió a sus tropas al mando del $d u x$ Ibbas para enfrentarse al visigodo. El combate se saldó con la huida de Gesaleico a África, donde pidió ayuda a los vándalos. ${ }^{10}$ Poco después regresaría a Occidente para intentar recuperar su trono, pero finalmente cayó definitivamente derrotado, siendo a continuación ejecutado a manos del propio Ibbas. ${ }^{11}$

Dado que Amalarico era aún un niño cuando fue promocionado al trono visigodo, Teodorico se hizo personalmente cargo de la regencia de su nieto hasta que permitió que este reinara en solitario, lo cual no ocurriría hasta el final del reinado del ostrogodo, entre los años 524 y el 526. ${ }^{12}$ Hasta entonces, el monarca ostrogodo se hizo con el control factual del reino visigodo (Díaz, Valverde Castro, 2007: $36 \mathrm{I}) \cdot{ }^{13} \mathrm{Ni}$ siquiera mantuvo unas mínimas apariencias, gobernando en nombre de su nieto, sino que lo hizo en el suyo propio; una posición que amparó en el supuesto objetivo de evitar el levantamiento de hostilidades entre los visigodos y la aristocracia hispanorromana (Ibidem: 364). Las propias fuentes, sean estas cronísticas, historiográficas o conciliares, transmiten explícitamente esta idea. ${ }^{14}$

\footnotetext{
${ }^{10}$ Chron. Caesar. (a. 510), 91a. 493-495: «[...] Quo anno idem Gesalecus ab Helbane Theodorici Italorum regis duce ab Hispania fugatus Africam petit»; Isid. Hisp., Hist. 38, I-3: «Inde profectus ad Africam Wandalorum suffragium poscit, quo in regnum posset restitui».

${ }^{11}$ Chron. Caesar. (a. 513), 94a, 52I-523: «His consulibus, Gisalecus de Afric rediens ob metum Helbanis Aquitaniam petiit ibique latuit annum unum"; Isid. Hisp., Hist. 38, red. larga, 4-I4: "Quid dum impetrasset auxilium, mox de Africa rediens ob metum Theuderici Aquitaniam petiit ibique anno uno delitiscens Spaniam reuertitur atque ab Ebbane Theuderici regis duce duodecimo a Barcinona urbe miliario commisso proelio in fugam uertitur captusque trans flumen Druentium Galliarum interiit, sicque prius honorem, postea uitam amisit».

${ }^{12}$ Chron. Caesar. (a. 524), 108a, 605-606: «His consulibus, Amalaricus Gotthorum rex efficitur. Regnat annis V",

${ }_{13}$ Chron. Caesar. (a. 513), 94b, 524-525: «Post Alaricum Theodoricus Italie rex Gotthos regit in Hispania an. XV, Amalarici paruuli tutelam gerens»; Isid. Hisp., Hist. 37, I2-I5: «Ibi moratus quousque etiam regni fascibus a Theuderico fugae ignominia priuaretur». El trabajo de referencia referido a este período es: García Iglesias, 1975.

${ }^{14}$ Chron. Caesar. (a. 513), 94b, 524-525; Isid. Hisp., Hist. 39, red. larga: "Aera DXLVIIII, anno uicessimo primo imperii Anastasii Theudericus junior [...] rursus extincto Gisaleico rege Gothorum Spaniae regnum, xv annis obtinuit, quod superstes Amalarico nepoti suo reliquit». Los contemporáneos concilios de Tarragona y Gerona se datan en función de los años de reinado de Teodorico, no de su nieto. Conc. Tarrac. (a. 516), Praef. 28-29: «In nominee Christi habita synodus Terracona, anno VI Theoderici regis, consulate Petri, sub die octauo Idus Nouembres»; Conc. Gervnd. (a. 5I7), Praef:: «In nominee Christi synodus habita Gerunda, anno septimo Teuderici regis, sexto Idus Iunias, Agapeto uiro clarissimo consl.» Ed. Martínez Díez, Rodríguez, I984:
}

Como soberano de facto, Teodorico mostró cierta preocupación por los asuntos hispanos. ${ }^{15}$ Por ejemplo, intentó imponer un mayor control sobre la tributación y la gestión del patrimonio regio en Hispania, poniendo coto a la corrupción en estas esferas de actuación. Asimismo, también estableció medidas para mejorar la deficiente gestión de la actividad comercial, entre otras disposiciones. ${ }^{16}$ Es posible que estas iniciativas hubiesen respondido a una concepción del territorio hispano por parte de Teodorico como una fuente de ingresos $(\mathrm{Ku}-$ likowski, 2004: 262-263; Thompson, 20II [I969]: 22; Barbero, Vigil, 2012 [1970]: 78). De hecho, el testimonio de Procopio recoge que la población peninsular estaba obligada al pago de impuestos directamente a los ostrogodos, al menos hasta el fin del período de tutela sobre Amalarico. ${ }^{17}$ Con todo, independientemente de los intereses que guardase Teodorico en relación a los dominios peninsulares que regentaba, se observa un esfuerzo por imponer un gobierno efectivo y eficaz en Hispania a través de agentes de poder delegados (Castellanos, 2008: 163).

Mucha menos información contamos en lo referido al reinado en solitario de Amalarico (526-53I). De hecho, en lo que respecta a la vertiente secular de su gobierno, la única información disponible se refiere a sus últimos días de reinado y a las circunstancias que giraron en torno a su muerte, las cuales pueden permitirnos aproximarnos a las dinámicas de poder vigentes estos años. Respecto a esta, las fuentes son bastante contradictorias, coincidiendo únicamente a la hora de considerarla una muerte violenta. Mientras Isidoro de Sevilla atribuye directa-

\footnotetext{
27I-284.

${ }^{15}$ Respecto al alcance geográfico de la dominación visigoda sobre Hispania en estos momentos, optamos por la postura minimalista, la cual defiende una dominación restringida al territorio de la Tarraconense. Kulikowski, 2004: 265 .

${ }^{16}$ Cassiod., Var. V, 35 y 39. Ed. A. Giardina, Cecconi, Tantillo, 2014: 174, 178-I80. No obstante, el reino visigodo siguió existiendo de iure como una entidad política independiente de la ostrogoda. Díaz, Valverde, 2007: 364.

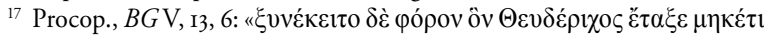

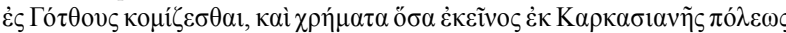

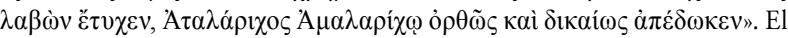
mismo autor confirma el interés económico de Teodorico en Hispania. $B G \mathrm{~V}$,

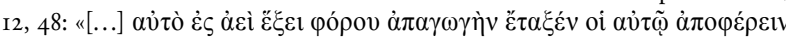

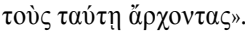


mente a los godos la muerte del rey godo, ${ }^{18}$ las crónicas se inclinan por culpar a los francos, al producirse esta justo después de una importante derrota frente a estos. ${ }^{19}$ Después tendríamos el testimonio de Gregorio de Tours, quien posiblemente a sabiendas de la confusión que rodeaba este asunto, prefirió optar por recoger un relato más ambiguo, sin culpar a ningún agente en concreto del asesinato de Amalarico. ${ }^{20}$ Esta misma ambigüedad domina la entrada de Jordanes en su Getica, presumiblemente la fuente más cercana a los hechos. ${ }^{21}$ La propia naturaleza contradictoria de los distintos testimonios, a lo que se le suma la escasez y parquedad informativa de estos, nos impiden establecer un orden más o menos claro de los acontecimientos, forzándonos a entrar en el puro campo de la especulación. A pesar de todo, consideramos que no sería una exageración atribuir la muerte de Amalarico a su propia gente, en concreto a aquellos de sus opositores que vieron en la derrota frente a los francos el contexto propicio para acabar con él. Esta oposición interna queda recogida en las fuentes cuando se dice de Amalarico que se ganó el odio de todos..$^{22}$ Aun tratándose de una clara exageración, lo cierto es que la

\footnotetext{
${ }^{18}$ Isid. Hisp., Hist. 40, red. larga: «Aera DLXIIII, anno imperii Iustiniani I, regresso Italiam Theuderico, Amalaricus nepos eius annis V regnauit. Qui cum ab Hildeberto Francorum rege apud Narbonam proelio superatus fuisset Barcionam trepidus fugiit effectusque omnium contemptibilis ab exercitu iugulatus interiit».

${ }^{19}$ Chron. Caesar. (a. 53I), II5a, 640-643: «His consulibus, Amalaricus cum Hildiberto Francorum regi in Galia superatus Narbonensi in proelio Barcinonem fugiens uenit, ibique a Franco nomini Bessone angone percussus interiit»; Fredeg., Chron. III, 30: «Amalricus filius Alarici sororem eorum in matrimonium accipit, per quam Barcenona a Childerico et Francis occisus est»; III, 4I: «Post haec Childebertus et Chlotacharius Spanis adpetunt easque partem maxima depopulati sunt. Amalricum regem Barcenona interficiunt $[\ldots] »$.

${ }^{20}$ Greg. Tur., DLH III, Io, 2-8: «Amalaricus vero haec audiens, anves ad fugiendum parat. Porro inminente Childebertho, cum Amalaricus navem deberet ascendere, ei in mentem venit, multitudinem se praetiosorum lapidum in suo thesauro reliquisse. Cumque ad eosdem petendus in civitatem regrederetur, $a b$ exercitu a porte exclusus est. Videns autem, se non posse evadere, ad eclesiam christianorum confugire coepit. Sed priusquam limina sancta contingerit, unus emissam manum lanciam eum mortali ictu sauciavit, ibique decidens reddedit spiritum».

${ }^{21}$ Iord., Get. LVIII, 302, 17-20: «qui Amalaricus, in ipsa adulescentia Francorum fraudibus irretitus, regnum cum vita amisit. Post quem Thiudis tutor idem regnum ipse invadens, Francorum insidiosam calumniam de Hispaniis pepulit, et usque dum viveret, Vesegothas continuit». Ed. Giunta, Grillone, 1991: 124.

${ }^{22}$ Isid. Hisp., Hist. 40, 4-9 red. larga: "Qui cum ab Hildeberto Francorum rege apud Narbonam proelio superatus fuisset Barcinonam trepidus fugiit effectusque omnium contemptibilis ab exercitu iugulatus interiit».
}

noticia revela ese contexto de discordia entre determinados sectores de la aristocracia visigoda, y que consideramos que marcó todo su reinado. Entre tales grupos, suponemos que algunos de estos estaban integrados por antiguos miembros de la facción del difunto Gesaleico que se vieron desplazados con la llegada al poder de la facción ostrogoda liderada por Teodorico y Amalarico (Fuentes Hinojo, 1996: I8-19). Sin embargo, su mayor amenaza interna fue sin dudas el grupo político encabezado por el general ostrogodo Teudis. No sería, por tanto, descabellado pensar que Teudis estuvo detrás del asesinato de Amalarico (Orlandis, 1962: 70; Thompson, 20II [I969]: 26). ${ }^{23} \mathrm{~A}$ fin de cuentas, fue esta circunstancia la que le permitió acceder al trono visigodo. ${ }^{24}$

El poder de Teudis fue creciendo exponencialmente desde los tiempos de la regencia de Teodorico, quien originalmente le designó como tutor del propio Amalarico y como comandante militar en Hispania. ${ }^{25}$ Dada la dependencia política de Amalarico en los tiempos de la regencia y la propia distancia de Teodorico, lo que le impedía ejercer un control directo de los asuntos hispanos, Teudis pudo actuar con total independencia (Fuentes Hinojo, 1996: 18-19). ${ }^{26}$ Desde ese momento, el general ostrogodo invirtió importantes esfuerzos en ampliar su poder y su base de apoyos, presumiblemente con el objetivo de optar algún día al trono. Lo más probable es que Teudis acabase atrayendo a parte de esos mismos sectores aristocráticos que en su día apoyaron a Gesaleico. A estos, se le deben sumar aquellos

\footnotetext{
${ }^{23}$ Hacia esta dirección apunta el testimonio de Isidoro de Sevilla. Isid. Hisp., Hist. 43, red. larga, 9-I5: «Fertur autem inter effusionem sanguinis coniurasse, ne quis interficeret percurssorem, dicens congruam meriti recepisse uicissitudinem, quod et ipse priuatus ducem suum sollicittum occiderit».

${ }^{24}$ Iord., Get. LVIII, 302, 17-20; Greg. Tur., DLH III, 30, 6: «Post Amalaricum vero Theuda rex ordinatus est in Hispaniis»; Isid. Hisp., Hist. 4I, red. breve, I-4: «Aera DLXVIIII imperatoris Iustiniani, post Amalaricum Theudis in Hispania creatur in regnum per annos XVI menses V [...]».

${ }^{25}$ Iord., Get. LVIII, 302, 15-17: «nam et Thiudem suum armigerum, post mortem Halarici generi, tutorem in Hispaniae regno Amalarici nepotis constituit». Algunos autores han propuesto que el objetivo a perseguir por Teodorico era coartar el posible ascenso de potenciales candidatos alternativos al trono visigodo. Schwarcz, 2002.

${ }^{26}$ Procopio de Cesarea llegó a decir de Teudis que actuó como un tirano antes de su llegada al trono. Procop., $B G, \mathrm{~V}$, I2, 51: «[...] Гó $\tau \theta \omega v \mu \varepsilon \grave{\varepsilon} v$

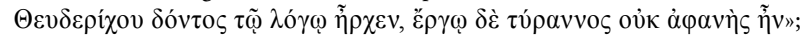

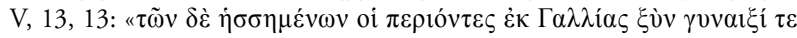

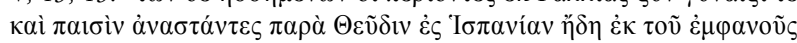

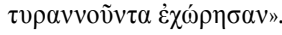


otros grupos que se fueron desencantando poco a poco del gobierno de Teodorico, primero, y de Amalarico, después. Asimismo, Teudis también se movió con habilidad para crear posiblemente la que sería la comitiva militar privada más importante del reino, una cuestión para nada baladí, puesto que la posesión de un amplio séquito constituía en sí mismo un marcador de influencia fundamental para todo aquel que aspirase a alcanzar altas cotas de poder por encima de otros, más en un contexto de inestabilidad militar (Barbero, Vigil, 1978: 39; Pérez Sánchez, 1989: 58-69; Halsall, 2003: 25; Petersen, 2013: 63-67). Para poder aglutinar tal comitiva armada, Teudis requería una importante masa de riquezas que le permitiese costearla (Jiménez Garnica, 20I0: 236-238). ${ }^{27}$ Es aquí donde se enmarca uno de los episodios más conocidos de la vida de Teudis, transmitido por Procopio. Nos referimos a sus nupcias con una importante y rica aristócrata hispanorromana, las cuales se dice que le reportaron una destacada riqueza con las que pudo sufragar el coste de un cuerpo militar profesionalizado (Petersen, 2013: I67-I69). ${ }^{28}$ Todos estos movimientos le acabarían convirtiendo en el verdadero hombre fuerte del reino, lo que evidentemente redundaba en detrimento de los intereses del monarca ostrogodo y su nieto. A la vista de tales logros de Teudis, podemos afirmar que el principal hándicap de Amalarico fue precisamente el período de regencia de su abuelo, el cual permitió a su principal rival construir unas redes de apoyo fuertes y poderosas con las que él no pudo competir cuando reinó en solitario.

El propio Teodorico habría intentado limitar el creciente poder de su comandante delegado en Hispania. De hecho, llegó a convocarle a la corte de Rávena, pre-

\footnotetext{
${ }^{27}$ A esto se le suma la propia importancia que tenía la propia acumulación de riqueza como marcador en sí mismo de poder. Tal y como afirma L. Sarti (2013: 225) aplicado al caso franco, «the first step of every potentate planning to take over power was therefore to acquire possession of a large amount of riches to constitute such a treasury».

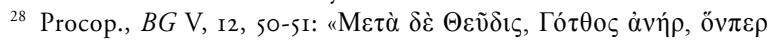

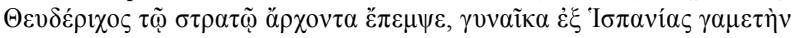

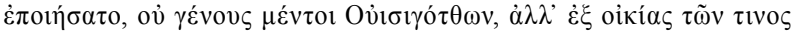

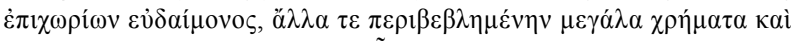

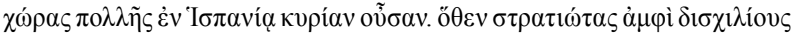

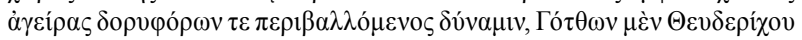

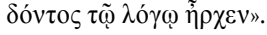

visiblemente con el objetivo de pedirle una rendición de cuentas y deponerle. Sin embargo, Teudis, en un acto de atrevimiento, rehusó obedecer el requerimiento del ostrogodo. Lo más sorprendente es la ausencia aparente de represalias por parte de Teodorico, dando muestra aún más patente del enorme poder de su subordinado. ${ }^{29}$ Es posible que el rey ostrogodo hubiese renunciado a castigar la osadía de Teudis ante el miedo a que la apertura de un conflicto con él facilitase un ataque de los francos o incluso el estallido de revueltas entre los visigodos que pudiesen complicar aún más la situación (Fuentes Hinojo, 1996: I8-19; Díaz, Valverde, 2007: 369). ${ }^{30}$ Ahora bien, no debemos ver necesariamente un descontento de las élites visigodas con los ostrogodos, con quienes podían entrar en colaboración de acuerdo a intereses mutuos. Este peligro de rebelión de los visigodos habría procedido únicamente de determinados sectores perjudicados por la dominación ostrogoda, pero ni mucho se habría tratado de una actitud generalizada entre toda la aristocracia visigoda. ${ }^{31}$ No se trató, por tanto, de una lucha entre ostrogodos y visigodos, ${ }^{32}$ como algunos han defendido (Fuentes Hinojo, 1996), sino que se trató de un choque entre facciones políticas, integradas cada una por sectores poblacionales de distintos orígenes que optaron por aglutinarse en torno a un determinado líder.

Reinando ya en solitario, Amalarico también habría abordado el problema de Teudis, intentando minar el poder de su poderoso rival con el nombramiento de un prefecto para Hispania, que recayó en la figura de

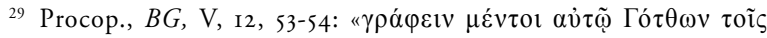

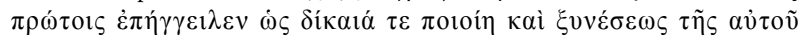

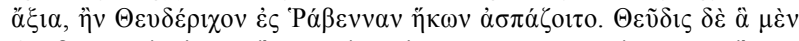

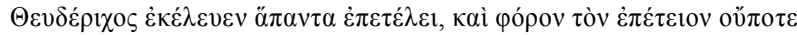

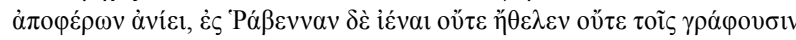
$\dot{\varepsilon} \pi \eta \gamma \gamma \dot{\varepsilon} \lambda \lambda \varepsilon \tau 0 »$.

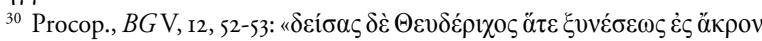

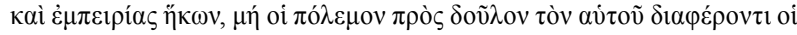

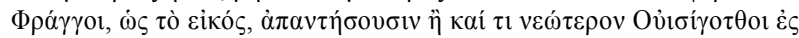

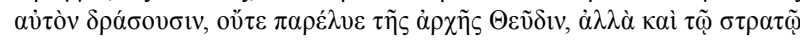

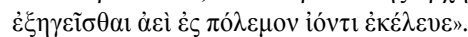

${ }_{31}$ Una postura diferente en Thompson, 20II [1969]: 23.

${ }^{32}$ De hecho, tenemos constancia de que en estas primeras décadas del siglo VI se fomentó la fusión entre ambos componentes poblacionales. Procop.,

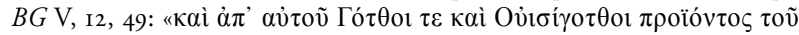

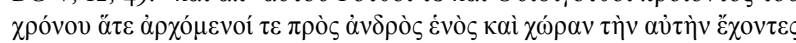

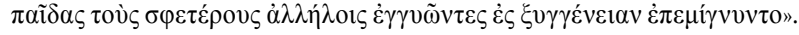


Esteban. ${ }^{33}$ Se trataba de un cargo específico que, más que estar destinado a dar continuidad a las antiguas estructuras administrativas romanas, se tomó directamente de la cancillería ostrogoda con el objetivo principal de promocionar a la cabeza de la gestión militar y administrativa del reino a alguien de la plena confianza del monarca, en detrimento de Teudis. ${ }^{34}$ Estimamos que el propósito a perseguir con este nombramiento habría sido ante todo colocar a Esteban en una posición superior a su rival, con el fin de estrechar el margen de maniobra de Teudis. ${ }^{35}$ Prueba de que este cargo se concibió como una forma de perjudicar a este último, sabemos que Teudis, después de llegar al trono, promovió la destitución de Esteban, así como la disolución de la prefectura, de la cual no volveremos a tener constancia de su existencia en momentos posteriores de la historia visigoda. ${ }^{36}$

Dentro de la batería de acciones destinadas a limitar el poder de Teudis, insertamos también, al final de la regencia de Teodorico, la entrega a Amalarico del thesaurum visigodo que los ostrogodos se apropiaron y llevaron a Rávena después de entrar con sus tropas en Carcasona, donde se custodiaba una parte importante del patrimonio regio de los visigodos. ${ }^{37}$ Este movimiento debemos entenderlo, no solo como la devolución

\footnotetext{
${ }^{33}$ Chron. Caesar. (a. 523), I13a, 627-628: «His diebus, Stephanus Hispaniarum praefectus efficitur [...]».

${ }^{34}$ Sobre el papel de esta figura en la administración ostrogoda, Bjornlie, 20I6: 6I. Thompson, 20II [I969]: 24-25 homologó este cargo con la prefectura del pretorio del Imperio romano tardío. Si ponemos el foco en el caso ostrogodo, la naturaleza militar del cargo queda puesta de manifiesto en el perfil castrense de sus titulares, como ocurrió en el caso de Liberio como prefecto del pretorio para la Galia. De este mismo se sabe que recibió importantes atribuciones militares para el gobierno de la Galia. Véase, O’Donnel, I98I: 46-47; Delaplace, 2003: 497; Arnold, 2016: 87-88.

${ }^{35}$ En una línea no muy alejada de la aquí propuesta, A. Barbero y $\mathrm{M}^{\mathrm{a}}$. I. Loring (2005: 177) propusieron que la elección de Esteban fue concebida por Amalarico como una vía de escape de la tutela de Teudis.

${ }^{36}$ Chron. Caesar. (a. 529), 13a, 628-629: «[...] qui tertio anno praefecturae suae in ciuitate Gerundensi in concilio distinctus est». Sobre esta cuestión, véase García Moreno, 1991: 157; Díaz, 2008: 354.

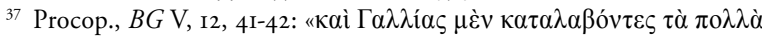

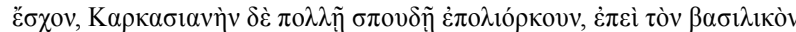

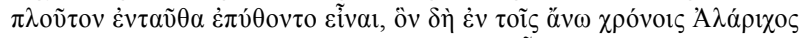

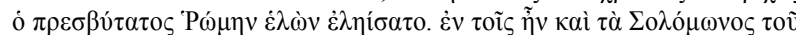

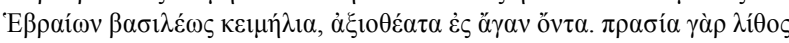

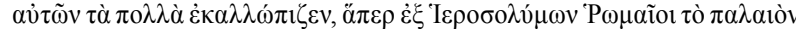
$\varepsilon \tilde{i} \lambda$ ov». Esta apropiación del tesoro visigodo fue uno de los factores que permitió a Teodorico mantener su dominación sobre los visigodos. Arce, 20II: 85-86.
}

simbólica de la soberanía a los visigodos y a sus titulares regios, ${ }^{38}$ sino como la adquisición del instrumento que permitía al monarca visigodo, aparte de exteriorizar la riqueza a su disposición, actuar de forma independiente para construir sus propias redes de apoyo entre la aristocracia a través de la redistribución de la riqueza a su disposición, más a la vista del importante patrimonio que Teudis fue acumulando durante esos años. Ante la riqueza de este último, la monarquía tenía que reaccionar para manifestar una fortuna superior (Barbero, Vigil, I978: I05, I70), siendo el tesoro la mejor forma de exteriorizar, ya no solo la riqueza regia, sino también la propia potencialidad de su redistribución a la aristocracia. ${ }^{39}$ El tesoro regio sería así empleado en el juego de concesiones hechas a la aristocracia del reino para atraer su apoyo y consolidar así el poder del monarca (Schmidt, 2003: 12). Sin embargo, es posible que tales medidas llegasen demasiado tarde, resultando bastante complicado revertir un poder, como era el de Teudis, que, aparte de encontrarse bastante consolidado, seguía creciendo sin posibilidad de control.

\section{EL PRAGMATISMO DE AMALARICO EN LA ESFERA ECLESIÁSTICA}

Resta a continuación aproximarnos a una vertiente del reinado de Amalarico que suele quedar bastante desdibujada por la historiografía. Nos referimos a su actitud hacia la Iglesia hispana. De nuevo aquí los historiadores han hecho una lectura excesivamente confiada de las fuentes narrativas disponibles, al mismo tiempo que han ignorado otros testimonios que, aun de forma indirecta, revelan una imagen diferente de las relaciones de Amalarico con la religión católica y sus principales representantes: los obispos. En concreto, el problema deriva de la interpretación que se ha hecho de una conocida noticia de Gregorio de Tours en la que se recogen los supuestos maltratos a los que Amalarico

\footnotetext{
38 Entendiendo el thesaurum en este sentido simbólico, Díaz, Valverde, 2000: 69; Gasparri, 2004: 53.

39 Tales dinámicas se asimilarían en cierta manera a las del Imperio en Oriente. Delmaire, 1989.
} 
sometió a su esposa, la reina Clotilde -hermana a su vez de los monarcas merovingios reinantes-, según el autor turonense, a causa de su fe católica. Presumiblemente, estos agravios habrían provocado la incursión merovingia al reino de Amalarico, con el consiguiente saqueo de ciudades. ${ }^{40}$ Esta visión ha sido aceptada literalmente por buena parte de la historiografía, considerando así a Amalarico un rey intolerante con la religión católica. ${ }^{41}$ Sin embargo, esta postura no se sostiene a la vista del resto de datos disponibles. En primer lugar, este anticatolicismo no permite entender por qué Amalarico aceptó inicialmente en matrimonio a la católica Clotilde (Dumézil, 2006: 257), ${ }^{42}$ a pesar de que Procopio aduzca la razón del miedo a los francos como justificación. ${ }^{43}$ Como explicación alternativa, es posible que en realidad el autor turonense hubiese buscado justificar en argumentos de tipo religioso un ataque que en realidad respondió a otros intereses, pero que le servía para denostar al arrianismo y sus prosélitos. ${ }^{44}$ Tampoco descartamos que los propios merovingios, en

\footnotetext{
${ }^{40}$ Greg. Tur., DLH, III, IO, I6-20, I-2: «Quod certissime Childeberthus cognoscens, ab Arverno rediit et Hispaniam propter sororem suam Chlotchildem dirigit. Haec vero multas insidias ab Amalarico viro suo propter fidem catholicam patiebatur. Nam plerumque procedente illa ad sanotam eclesiam, stercora et diversos fetores super eam proieci imperabat, ad extremum autem tant eam crudelitate dicitur caecidisse, ut infectum de proprio sanguine sudarium fratri transmitteret, unde ille maxime commotus, Hispanias appetivit»;

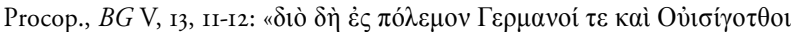

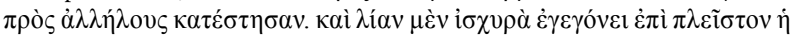

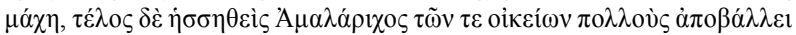

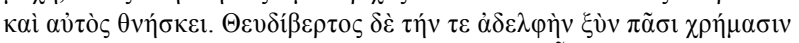

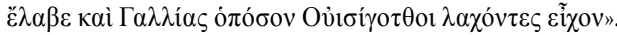

${ }^{41}$ Por ejemplo, Orlandis, 1962: 69; García Iglesias, 1975: 107. Véase también Thompson, 20II [1969]: 25. Otros autores ofrecen una lectura alejada de las explicaciones religiosas, aunque siguen confiando en el testimonio del turonense. Fuentes Hinojo, 1996: 2I.

${ }^{42}$ Greg. Tur., $D L H$ III, I, I7-I8, I-2: «Cumque magna virtute pollerent et eis de exercitu rubor cupiosus inesset, Amalaricus, filius Alarici, rex Hispaniae sororem eorum in matrimonio postolat, quo dille clementer indulgent et eam ipse in regionem Hispaniae cum magnorum ornamentorum mole transmittut».

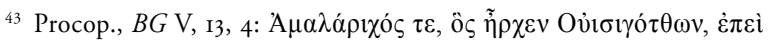

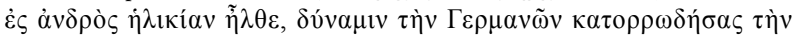

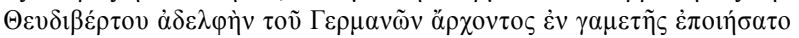

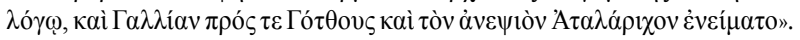
Su testimonio recoge una confusión en lo referido a la filiación de Clotilde con los merovingios. En lugar de considerar a la esposa de Amalarico como tía de Teudeberto, la confunde con su hermana. Clotilde sí tenía vínculos fraternales con Childeberto, Clotario y Teoderico.

${ }^{44}$ La demonización del enemigo arriano, tergiversando los hechos con el fin de reforzar sus argumentos, es un elemento recurrente en la obra de Gregorio de Tours. Véase Isla, I990; Moorhead, I995; Wood, 2003 [1985]: I40.
}

concreto Childeberto, hubiesen denunciado el maltrato, con independencia de su veracidad, como excusa para atacar el reino visigodo y poder ofrecerle así a su gente una oportunidad de enriquecerse por la vía del pillaje (Ibidem). ${ }^{45}$

Por otro lado, hay otro argumento de peso que redunda en contra del supuesto anticatolicismo de Amalarico, como son las amistosas relaciones que, al menos en apariencia, mantuvo con el episcopado hispano. Así lo revelan las actas del II Concilio de Toledo, celebrado en el ańo 53I y presidido por obispo de Toledo Montano. ${ }^{46}$ En ellas los obispos asistentes dataron las sesiones de acuerdo a los años de reinado de Amalarico. ${ }^{47}$ Asimismo, en las actas también queda recogida la petición por parte de los obispos a Amalarico de permiso para poder celebrar un nuevo concilio en un futuro relativamente cercano. Ambos detalles, lejos de suponer una cuestión baladí, constituyen la primera evidencia escrita que testimonia la influencia política de la monarquía visigoda sobre estos espacios de la Meseta, puesto que los obispos aceptan explícitamente, no solo la autoridad secular de Amalarico, sino la capacidad de este de decidir sobre los asuntos eclesiásticos. Para llegar a este punto, Amalarico tuvo que haber entablado relaciones con los obispos de este sector geográfico, siendo posiblemente el primer monarca visigodo que mostró un interés por ello. Vemos por tanto que, al menos

\footnotetext{
${ }^{45}$ Como refuerzo a esta argumentación, nos hacemos eco de las palabras de E. James (2009: 9I): «family honour' was often invoked by the Merovingians as an occasion for war; it is difficult to know whether this was merely a cloak for other more pressing and material reasons».

${ }^{46}$ Conc. II Tolet. (a. 63I). Ed. Martínez Díez, Rodríguez, 1984: 345-346. Sobre la datación de este concilio, véase Schaferdiek, 1967; Barbero, 1989. Algunos historiadores prefieren obviar la existencia de estos trabajos e inclinarse por la fecha tradicional del 526/527. Collins, 2004: 37. Isidoro de Sevilla, por su parte, erró al situar la celebración de este concilio en tiempos de Teudis. Isid. Hisp., Hist. 4I, red. larga, 7-II: «[...] in unum apud Toletanam urbem conuenire et quaecumque ad ecclesiae disciplinam necessaria existerent, libere licenterque disponere». Ofreciendo otra interpretación a este testimonio del hispalense, Velázquez, 2000: 589.

${ }_{47}$ Conc. II Tolet. (a. 63I), I4-I6: «In nomine Domini apud Toletanam urbem sanctorum episcoporum praesentia conuenisset et de institutis Patrum canonumque decretis commemoratio haberetur, id nobis in unum positis placuit, ut si qua in antiquis canonibus minime commemorata sunt, salubri tractatu ac diligenti consideratione instituantur». A este concilio habrían asistido cinco obispos cercanos a la sede toledana, entre los que se encontrarían los titulares de las sedes de Complutum, Segobriga, Ercauica y Segontia, así como otros tres obispos procedentes de otras provincias eclesiásticas. García Moreno, 1988: 156-157. Sobre esta cuestión, véase también Pina Lucindo, 2013.
} 
en la esfera eclesiástica, Amalarico prestó una mayor atención a los asuntos hispanos que a los galos, para los cuales no contamos con testimonio alguno. ${ }^{48}$ Es cierto que el foco geográfico de actuación en la esfera secular siguió centrado en la Galia en estos momentos, ${ }^{49}$ no siendo hasta el reinado de Teudis cuando los esfuerzos visigodos se centraron, ahora ya sí en exclusiva, sobre el territorio hispano. ${ }^{50}$ Sin embargo, debemos reconocerle a Amalarico estas primeras tentativas de trasladar el foco de actuación sobre Hispania.

Es posible que la actitud de Amalarico hacia la religión y los obispos católicos hubiese venido inspirada también por su abuelo Teodorico, quien mantuvo en Italia una política de respetuosa tolerancia religiosa y una relación distendida con los obispos itálicos. ${ }^{51}$ En lo que respecta al territorio hispano (García Moreno, 1988), no descartamos incluso que los concilios de Tarragona y de Gerona celebrados durante su regencia se hubiesen llevado a cabo con su connivencia. ${ }^{52}$ Ahora bien, su intervención en la Iglesia hispana habría sido más bien indirecta, a través de la intermediación papal (Delaplace, 2003: 494; Castillo Maldonado, 2013: 233). Con todo, en líneas generales, Teodorico habría mantenido la independencia de acción de las iglesias hispanas (Castillo Maldonado, 20I5: 153).

Sobre las razones que pudieron motivar el acercamiento de Amalarico al episcopado hispano, conside-

\footnotetext{
${ }^{48}$ Discrepamos así con Velázquez, Ripoll, 2000: 525 y Castillo Maldonado, 2013: 237, quienes defienden que Amalarico ignoró los dominios hispanos. Tampoco aceptamos la opción contraria, aquella que habla de un supuesto plan de abandono de la Galia desde momentos bastante tempranos. Arce, 2005: 135. Por otro lado, es posible que ya el propio Amalarico hubiese desistido de recuperar los territorios perdidos en la Galia. A ello lleva a pensar su matrimonio con la princesa merovingia Clotilde, hija de Clodoveo, unas nupcias que no se entienden bajo la pretensión de una «reconquista» de los dominios en manos de los francos. Tampoco descartamos que este fuera un movimiento del propio Teudis, quien recordemos que tuteló las políticas de Amalarico durante buena parte de su reinado. Barbero, Loring, 2005: 178.

${ }^{49}$ Así lo revela su propia residencia en Narbona. García Moreno, I989: 94.

${ }^{50}$ Esta concentración política de los visigodos en el territorio galo durante las primeras décadas de la sexta centuria ha sido catalogada como el «complejo del reino de Tolosa», en otras palabras, la nostalgia del territorio perdido. García Moreno, 1991: 155. Véase también, D’Abadal, 1960: 63; Kulikowski, 2004: 26I-262; Barbero, Loring, 2005: 178.

${ }^{51}$ Sobre el particular, véase Saitta, 1994; Sardella, 1996; Lizzi Testa, 2016; Ozóg, 2016; Sessa, 2016.

52 Tengamos en cuenta que las actas de ambos concilios se datan por el reinado de Teodorico, lo que supone un reconocimiento implícito de lealtad al ostrogodo.
}

ramos que, a la vista de su frágil posición frente a la aristocracia militar del reino y, en concreto, frente a Teudis, tal aproximación fue una reacción más a su situación política interna, esto es, una estrategia de supervivencia política basada en la búsqueda de apoyos en otros sectores poderosos de la sociedad hispana..$^{53} \mathrm{El}$ episcopado hispano, dada su enorme influencia social y territorial (Ubric Rabaneda, 2004; Fuentes Hinojo, 2008; Bárenas Alonso, 2016; Poveda Arias, 2019), se prestaba una opción atractiva para extender sus redes de apoyo e influencia. La política de acercamiento al episcopado hispano nos revela así una imagen muy distinta del débil Amalarico en la esfera secular. En esta ocasión observamos un Amalarico pragmático, abierto a la Iglesia católica y a sus obispos, al ver en ellos una posibilidad de reforzarse frente a los enemigos internos.

Otra pregunta se nos plantea a la hora de entender por qué los obispos reunidos en el II Concilio de Toledo aceptaron, e incluso reclamaron, la injerencia regia en sus asuntos internos. Aquí consideramos que desempeñó un papel protagonista la figura de Montano de Toledo. Generalmente se piensa que eran los monarcas los que necesitaban de la colaboración episcopal para fortalecer su posición, pero no se suele hacer el camino contrario, planteándose que, en un esquema de reciprocidad, los obispos también podían tener intereses en recurrir a los poderes seculares vigentes, ya no solo para seguir ejerciendo con garantías su ministerio episcopal, sino también para obtener mayores cotas de poder. A pesar del carácter vitalicio de la posición episcopal, esta podía verse cuestionada si se desarrollaba un descontento creciente hacia el titular de una sede determinada. En consecuencia, al igual que los monarcas, los obispos estaban también bastante lejos de sentirse seguros ante grupos rivales que aspiraban a ocupar esa misma posición. A fin de cuentas, tal y como afirma P. Castillo, «sería ilusorio pretender que el obispo consiguió un consenso unánime en torno a una persona» (Castillo Maldonado, 2007: 267). ${ }^{54}$ Aplicado al caso

\footnotetext{
53 Ofreciendo una lectura alternativa, Castillo Maldonado, 20I3: 234-235

${ }^{54}$ Este mismo autor ofrece otras afirmaciones igualmente elocuentes como refuerzo de nuestra argumentación: «el clero no era monolítico y (...) la posición de los obispos no siempre era tan estable como pudiera entenderse»;
} 
de Montano, en caso de darle validez al testimonio ofrecido por el De Viris Illustribus de Ildefonso de Toledo, se sabe que en un momento dado la autoridad del obispo de Toledo en el seno su sede fue cuestionada al ser acusado de caer, presuntamente, en «relaciones impuras». ${ }^{55}$ Es cierto que logró librarse de tales acusaciones. Sin embargo, el episodio en cuestión revela la existencia de distintas facciones en la iglesia toledana que aspiraban a ocupar la cátedra episcopal, ${ }^{56}$ lo que forzaba a Montano a desarrollar estrategias de supervivencia que le permitiesen imponerse sobre aquellos que competían con él y aspiraban a promocionar a un prelado alternativo integrante de su facción. No sería extraño pensar que entre tales estrategias, Montano hubiese decidido entablar relaciones con Amalarico, quien, como hemos puesto de relieve, se veía igualmente necesitado de apoyos para reforzar su débil posición. En una actitud de pragmatismo muy propia de los obispos hispanos (Ubric Rabaneda, 20I5), ${ }^{57}$ el prelado de Toledo vio así en las nuevas monarquías que nacieron a partir de la descomposición del Imperio en Occidente una oportunidad para la consecución de sus propios objetivos, sin que las barreras religiosas supusiesen un obstáculo.

En consecuencia, debemos entender las relaciones entre Montano y Amalarico, no en un sentido institucional, es decir, de alianza entre Iglesia y monarquía, sino en términos personales y de reciprocidad, ${ }^{58}$ única-

«tan erróneo es considerar que el episcopado hispano fue monolítico en sus posiciones políticas, como pretender que en las distintas diócesis no había facción ni querella alguna». Ibidem: 27I, 276.

55 Ild. Tolet., De Vir. Illustr. Praef., 29-35: «Nam Montanus sedis eius beatissimus praesul ut a se coniugalis conuersationis infamiam propulsaret, tamdiu adsumptos ueste candentes narratur tenuisse carbones, donec Domino consecrans oblationem totius per semetipsum compleret missae celebritatem; quo sacrificio expleto, prunarum ignis cum decore uestis adeo in concordiam uenit, ut nec uestis uim extingueret ignis, nec uis ignis statum laederet uestis»; III, 35-38: «Hic uir antiquissima fidelique relatione narratur ad exprobrationem infamiae tamdiu prunas tenuisse in uestimentis ardentes donec coram sedis suae sacro altari totius missae celebritatem per semetipsum expleret». Ed. Codoñer, 2007: 599, 605.

56 Sobre los faccionalismos en la Iglesia hispana tardoantigua, remitimos de nuevo al trabajo de Castillo Maldonado, 2007.

57 Una actitud similar mostraron los obispos en otros espacios del Occidente post-imperial. Véase Van Dam, I985; Mathisen, 1992; Díaz, 2016.

${ }^{58}$ Una opinión distinta se plantea en Castillo Maldonado, 2013: 236, quien considera que en este punto la Iglesia quedó en una posición de inferioridad frente a la monarquía visigoda. mente como dos individuos que entablan una relación de apoyo mutuo con una motivación, aparentemente, de eminente carácter personal, como era hacer frente a la fragilidad de su posición interna. Obviamente, el apoyo regio a las pretensiones de Montano no era automático, ${ }^{59}$ sino que el diálogo y la negociación entre partes resultaba fundamental. En este caso, entendemos que Montano ofreció a Amalarico su apoyo a cambio de que el visigodo hiciese lo propio, reforzándose así mutuamente. En concreto, esta relación habría llevado a un reconocimiento del poder de cada uno en sus respectivas esferas de actuación, uno en la eclesiástica y otro en la meramente secular. En concreto, Montano lograría que Amalarico le reconociese su autoridad como obispo metropolitano, una posición que, aparentemente, reclamó la sede toledana por primera vez en estos momentos, ${ }^{60}$ en un movimiento que interpretamos que buscó, ante todo, reforzarse frente a sus opositores. Es más, creemos que las propias declaraciones de las actas conciliares en favor del monarca confirman en cierta manera el papel del monarca visigodo en la legitimación de la nueva provincia eclesiástica de Car-

59 Defiende esta idea en un plano general: Dumézil, 2006: 72-73.

${ }^{60}$ En consecuencia, se creó una nueva provincia eclesiástica, desgajada de la Cartaginense. Las actas del II Concilio de Toledo, así como las cartas anexas, recogen la primera evidencia sobre la existencia de esta nueva provincia, denominada Carpetania. Conc. II Tolet. (a. 53I), 98-IO2: «Sane iuxta priorum canonum decreta concilium apud fratrem nostrum Montanum episcopum si Dominus uolerit futurum pronuntiamus, ita ut frater et coepiscopus noster Montanus, qui in metropoli est, ad comprouinciales nostros Domini sacerdotes litteras de congreganda synodo adveniente tempore debeat destinare»; I42I47: «Hac ergo uoce permotus, huius officii necessitudinem me suscepisse non nesciens, studere curaui ne cuiusquam perditi animam de manu mea Christus inquirat, praesertim cum Toletanae urbi metropolitanum priuilegium uetus consuetudo tradiderit et eo magis non solum parrociarum, sed et urbium cura huius urbis sollicitet sacerdotem»; 203-206: "[...] et licet sint unius fidei copula nobiscum in Christo conexi, tamen nec prouinciae priuilegiis nec rerum domini noscitur utilitatibus conuenire, quia iam ad ipsum huiuscemodi fama perlata est». En estos textos Montano reclama la antigüedad de los privilegios metropolitanos de su sede, pero es posible que se trate únicamente de una estrategia del obispo toledano para imbuirse de una mayor legitimidad. Véase Martin, I998: 406. En el mismo sentido se interpreta la reclamación de la posición de metropolitano del obispo Asturio, predecesor de Montano, por parte de Ildefonso de Toledo, quien tenía sus propios intereses en ello. Ild. Tolet., De Vir. Illus. I, I-2: «Asturius post Audentium in Toleatana urbe sedis metropolis prouinciae Carthaginis pontifex successor obuenit». Véase Codoñer, 1972: 6I, 64; Orlandis, I980: II; Wood, 20I2b: 628-637. No obstante, hay otros sectores de la historiografía que prefieren dotar de credibilidad a los testimonios que apuntan a una mayor antigüedad de Toledo como sede metropolitana. García Moreno, I988: I59. 
petania, que recibiría así un reconocimiento exterior. ${ }^{61}$ Amalarico, por su parte, aparte de ampliar su base de apoyos, lograría también extender sus redes de influencia, en este caso a través de Montano, sobre una región que hasta estos momentos escapó al control político visigodo. Amalarico hizo así de sus relaciones con los poderes episcopales de la Península una estrategia de supervivencia política más. El nieto de Amalarico vio por tanto en la negociación con las élites eclesiásticas una manera de compensar su debilidad en otras esferas de poder. Posiblemente fue el primer monarca de la fase hispana que percibió con mejor atino la utilidad del diálogo con los poderes locales y regionales, ya no solo para reforzarse, sino para lograr una implantación y articulación efectiva de su poder sobre el territorio por encima de la vía militar (Castellanos, Martín Viso, 2005; Castellanos, 2008; Fernández, 2017).

\section{CONCLUSIONES}

En resumen, ciertamente el reinado de Amalarico no destacó como un período de grandes logros políticos o militares. De hecho, la imagen que transmitirán las fuentes de su reinado vendrá marcada por la derrota militar que sufrió frente a los francos en el 53I, así como por las tensiones internas que dominaron las dinámicas de poder durante estos años. Esta situación no debe, sin embargo, permitir al historiador moderno dejarse llevar por los juicios de valor que transmiten las fuentes sobre esta figura. Al contrario, si obviamos los prejuicios negativos aplicados sobre Amalarico y las perspectivas teleológicas que dominan las interpretaciones sobre su reinado, se nos revela un individuo que, a pesar de las dificultades, fraguadas en su mayoría en el tiempo de la regencia de Teodorico, no quedó impasible ante la adversidad, sino que respondió en la medida de sus posibilidades para revertir la situación y fortalecerse frente a sus competidores. Una impresión más positiva de este monarca se obtiene en lo referido a su actitud frente al catolicismo y, en especial, frente a los obispos hispanos. Esto es, en contra de esa imagen negativa que transmiten las fuentes como un gobernante intolerante con el catolicismo, se nos revela un monarca pragmático en el ámbito religioso, capaz ya no solo de tolerar un dogma que no es el suyo, sino también de colaborar con su jerarquía eclesiástica para hacer frente a la debilidad crónica que experimentó en la esfera política.

\footnotetext{
${ }^{61}$ El mismo objetivo habría perseguido la presencia al II Concilio de Toledo de obispos procedentes de otras provincias eclesiásticas. También aquí se puede intuir de forma indirecta la influencia de Amalarico, puesto que dos de estos asistentes externos, los hermanos Justo de Urgell y Nebridio de Egara, eran dos obispos de reconocida afinidad al régimen visigodo. Conc. II Tolet. (a. 53I), Subscr. I22-I3I: «Nibridius in Christi nomine ecclesiae catholicae Egerensis episcopus hanc constitutionem consacerdotum meorum in Toletana urbe habitan, cum post aliquantum temporis aduenissem, saluwa auctoritate priscorum canonum relegi, probaui et subscripsi. / Iustus in Christi nomine ecclesiae catholicae Vrgellitanae episcopus hanc constituionem consacerdotum meorum in Toletana urbe habitam, cum post aliquantum temporis aduenissem, salua auctoritate priscorum canonu relegi, probaui et subscripsi». García Moreno, I997: 273. Ofrece una lectura distinta: Castillo Maldonado, 2010: 420.
} 


\section{FUENTES PRIMARIAS:}

Cassiodorus, Variae, V, ed. Giardina, Andrea, Cecconi, Giovanni Alberto, Tantillo, Ignazio (20I4): Flavio Magno Aurelio Cassiodoro Senatore. Varie, Volume II, Libri III-V, Roma, 'L'Erma' di Bretschneider.

Chronica Caesaraugustana, ed. Cardelle de Hartmann, Carmen (200I): Victoris Tvnnunensis Chronicom cum reliquiis ex consvlaribus Caesaravgustanis et Iohannis Biclarensis Chronicon, CC, Series Latina, I73A, Turnhout, Brepols.

Chronica Gallica A. SiI, ed. Burgess, Richard W. (200I): «The Gallic Chronicle of $5 \mathrm{II}$ : A New Critical Edition with a Brief Introduction", en Mathisen, Ralph W., Shanzer, Danuta (eds.), Society and Culture in Late Antique Gaul: Revisiting the Sources, Aldershot, Ashgate, p. 85-IOO.

Fredegarius, Chronicon, III, ed. y trad. Desgrugillers, Nathalie (201I): Frédegaire. Les Compilations, Partie IV. Texte latin du Ms B.n.F., lat. 109o, Clermont-Ferrand, Éditions Paleo, 20II.

Fredegarius, Chronicon, IV, ed. y trad. Devillers, Olivier, Meyers, Jean (200I): Frédégaire. Chronique des temps mérovingiens. Traduction, introduction et notes, Turnhout, Brepols.

Gregorius Turonensis, DeCEM Libri Historiae, ed. Krusch, Bruno, Levison, Wilhelm (195I): Gregorii Episcopi Turonensis Historiarum Libri X, MGH, Scriptores Rerum Merovingicarum, T. I, P. I, Hannover, Impensis Bibliopolii Hahniani.

Ildefonsus Toletanus, De Viris Illustribus, ed. Codoñer, Carmen (2007): Ildefonsi Toletani episcopi. De virginitate Sanctae Mariae; De cognitione baptismi; De itinere deserti; De viris illustribus, CC, Series Latina, II4A, Turnhout, Brepols.

Iordanes, Getica, ed. Giunta, Francesco, Grillone, Antonino (I99i): Iordanis de Origine actibusque Getarum, Roma, Istituto Storico Italiano per il Medio Evo.

Isidorus Hispalensis, HistoriaE, ed. y trad. Rodríguez Alonso, CristóBAL (1975): Las Historias de los godos, vándalos y suevos de Isidoro de Sevilla, León, Centro de Estudios e Investigación «San Isidoro»-Archivo Histórico Diocesano-Caja de Ahorros y Monte de Piedad de León.

La COLECCIÓN CANÓNICA HISPANA, IV, ed. Martínez Díez, GonZalo, Rodríguez, Félix (1984), Madrid, CSIC.

Procopius Caesariensis, De Bello Gothico, V-Vi, ed. Dewing, H. B. (1919): Procopius, III, History of the Wars, Books V and VI, London-New York, William Heinemann-G. P. Putnam's Sons.

\section{BIBLIOGRAFÍA:}

D’Abadal, Ramón (1960): Del reino de Tolosa al reino de Toledo, Madrid, Real Academia de la Historia.

ArCe, JAVier (2005): Bárbaros y romanos en Hispania (400-507 A. D.), Madrid, Marcial Pons.

ArCE, JAVIER (20II): Esperando a los árabes. Los visigodos en Hispania (507-7II), Madrid, Marcial Pons.

Arnold, Jonathan J. (2016): «Ostrogothic Provinces: Administration and Ideology», en Arnold, Jonathan J., Bjornlie, M. Shane, Sessa, Kristina (eds.), A Companion to Ostrogothic Italy, Leiden-Boston, Brill, p. 73-97.
Barbero, Abilio (1989): «Las divisiones eclesiásticas y las relaciones entre la Iglesia y el Estado en la Espańa de los siglos VI y VII», en Hidalgo de la Vega, $\mathrm{M}^{\mathrm{a}}$. José (ed.), La historia en el contexto de las ciencias humanas y sociales. Homenaje a Marcelo Vigil Pascual, Salamanca, Ediciones Universidad de Salamanca, p. I69-I9o.

Barbero, Abilio, Loring, Ma. Isabel (2005): «The Formation of the Sueve and Visigothic Kingdoms in Spain», en Fouracre, Paul (ed.), The New Cambridge Medieval History, I: c. 500-c.700, Cambridge, Cambridge University Press, p. 162-192.

Barbero, Abilio, Vigil, Marcelo (1978): La formación del feudalismo en la Península Ibérica, Barcelona, Crítica.

Barbero, Abilio, Vigil, Marcelo (2OI2): «Algunos aspectos de la feudalización del reino visigodo en relación con su organización financiera y militar", en Visigodos, cántabros y vascones en los orígenes sociales de la Reconquista, Pamplona, Urgoiti, p. 73-95 (ed. orig. 1970, Moneda y crédito, II2, p. 7I-ss).

Bárenas Alonso, Ramón (20I6): «El dominio episcopal sobre el territorio: competencias y recursos", Brocar, 40, p. 7-42. (https://doi.org/I0.18172/brocar.3239).

Bjornlie, M. Shane (20I6): «Governmental Administration», en Arnold, Jonathan J., Bjornlie, M. Shane, Sessa, Kristina (eds.), A Companion to Ostrogothic Italy, Leiden-Boston, Brill, p. 47-72.

Castellanos, Santiago (2007): Los godos y la cruz. Recaredo y la unidad de 'Spania', Madrid, Alianza Editorial.

Castellanos, Santiago (2008): «La construcción del poder político visigodo y los horizontes locales: canales de participación y de hostilidad", en Castellanos, Santiago, Martín Viso, Ińaki (eds.), De Roma a los bárbaros. Poder centraly horizontes locales en la cuenca del Duero, León, Universidad de León, p. 145-170.

Castellanos, Santiago, Martín Viso, IŃaki (2005): «The Local Articulation of Central Power in the North of the Iberian Peninsula (500-I000)", Early Medieval Europe, I3/I, p. I-43. (https://doi.org/I0.IIII/j.I468-0254.2005.00I47.X).

Castillo Maldonado, Pedro (2007): "In ecclesia contra ecclesiam: algunos ejemplos de disputas, violencias y facciones clericales en las iglesias", Antiquité Tardive, I5, p. $263-276$ (https://www.brepolsonline.net/doi/ abs/Io.I484/J.AT.2.303122).

Castillo Maldonado, Pedro (2010): «Concilios hispanos tardoantiguos: de asamblea religiosa a asamblea política», en Bravo, Gonzalo, González Salinero, Raúl (eds.), Toga y daga. Teoría y praxis de la politica en Roma, Madrid, Signifer, p. 417-434.

Castillo Maldonado, Pedro (2013): «Conflict and Compromise: The Spanish Catholic Bishops and the Arian Kingdom of Toledo (from Vouillé to Leovigild)», en Fear, Andrew, Fernández Ubiña, José, Marcos, Mar (eds.), The Role of the Bishop in Late Antiquity. Conflict and Compromise, London-New York, Bloomsbury, p. 229-244.

Castillo Maldonado, Pedro (20i5): «Católicos y arrianos en la Hispania visigoda. La conformación de un sistema único de dominación», en Fernández Ubiña, José, Quiroga Puertas, Alberto J., Ubric Rabaneda, Purificación (coords.), La Iglesia como sistema de dominación en la Antigüedad Tardia, Granada, Ediciones Universidad de Granada, p. 5I-7I

Codoñer, Carmen (1972): El 'De Viris Illustribus' de Ildefonso de Toledo. Estudio y edición critica, Salamanca, Universidad de Salamanca.

Collins, Roger (2004): La España visigoda, 409-7II, Barcelona, Crítica (ed. orig. 2004, Visigothic Spain 407-7II, Malden, Blackwell).

Delaplace, Christine (2003): «La Provence sous la domination ostrogothique (508-536)", Annales du Midi : revue archéologique, historique et philologique de la France méridionale, II5/244, p. 479-499. (https://doi.org/I0.3406/ anami.2003.4027). 
Delmaire, Roland (1989): Largesses sacrées et Res privata. L'aerarium impérial et son administration du IVe au VIe siècle, Roma, École Française de Rome.

DíAz, PABlo C. (2008): «El siglo VI en Galia e Hispania a través de las fuentes escritas", Zona Arqueológica, II, p. 348-363.

Díaz, Pablo C. (2016): «El obispo y las invasiones de los pueblos bárbaros», en Acerbi, Silvia, Marcos, Mar, Torres, Juana (eds.), El obispo en la Antigüedad tardía. Homenaje a Ramón Teja, Madrid, Editorial Trotta, p. 133-I49.

Díaz, Pablo C., Martínez Maza, Clelia, Sanz Huesma, Francisco JaVIER (2007): Hispania tardoantigua y visigoda, Madrid, Istmo.

Díaz, Pablo C., Valverde, Ma. Rosario (2000): «The Theoretical Strenght and Practical Weakness of the Visigothic Monarchy of Toledo", en Theuws, Frans C. W. J., Nelson, Janet L. (eds.), Rituals of Power. From Late Antiquity to the early Middle Ages, Leiden, Brill, p. 59-93.

Díaz, Pablo C., Valverde, Ma. Rosario (2007): «Goths Confronting Goths: Ostrogothic Political Relations in Hispania», en Barnish, Samuel J. B., Marazzi, Federico (eds.), The Ostrogoths: From the Migration Period to the Sixth Century, Woodbridge, The Boydell Press, p. 353-386.

DumÉzIL, BRuno (2006): Les racines chrétiennes de l'Europe : Conversion et liberté dans les royaumes barbares, Ve-VIIIe siècle, Paris, Fayard.

Fernández, Damí́n (20I7): Aristocrats and Statehood in Western Iberia, 300600 C.E., Philadelphia, University of Pennsylvania Press.

Fuentes Hinojo, Pablo (1996): «La obra política de Teudis y sus aportaciones a la construcción del reino visigodo de Toledo», En la España Medieval, 19, p. 9-36 (https://revistas.ucm.es/index.php/ELEM/article/ view/ELEM9696110009A).

Fuentes Hinojo, Pablo (2008): «Patrocinio eclesiástico, rituales de poder e historia urbana en la Hispania tardoantigua (siglos IV al VI)», Studia Historica. Historia Antigua, 26, p. 315-344. (https://revistas.usal.es/index. php/o213-2052/article/view/1617/1679).

García Iglesias, Luis (1975): «El intermedio ostrogodo en Hispania (507-549 d. C.)", Hispania Antiqua, I, p. 257-268.

García Moreno, Luis Agustín (1988): «Problemática de la Iglesia hispana durante la supremacía ostrogoda (507-549)», en Saranyana, José Ignacio, Tejero, Eloy (eds.), Hispania Christiana. Estudiso en honor del prof. Dr. José Orlandis Rovira en su septuagésimo aniversario, Pamplona, Ediciones Universidad de Navarra, p. I47-I60.

García Moreno, Luis Agustín (1989): Historia de España visigoda, Madrid, Cátedra.

García Moreno, Luis Agustín (199i): «Las invasiones, la ocupación de la península y las etapas hacia la unificación territorial», en Historia de España fundada por Ramón Menéndez Pelayo, III.2, España visigoda, Madrid, España-Calpe, p. 6I-2I8.

García Moreno, Luis Agustín (1997): «La monarquía visigoda y la Iglesia en Levante. Las raíces de un país", Hispania Sacra, 49, p. 253-277 (http://hispaniasacra.revistas.csic.es/index.php/hispaniasacra/article/download/669/667).

García Moreno, Luis Agustín (2008): Leovigildo. Unidad y diversidad de un reinado, Madrid, Real Academia de la Historia.

Gasparri, Stefano (2004): «Il tesoro del re», en Gelichi, Sauro, La Rocca, $\mathrm{M}^{\mathrm{a}}$. Cristina (eds.), Tesori. Forme di accumulazione della ricchezza nell'alto medioevo (secoli V-XI), Roma, Viella, p. 47-67.

Halsall, Guy (2003): Warfare and Society in the Barbarian West, 450-900, London, Routledge.

Halsall, GUY (2005): «The Sources and Their Interpretation», en Fouracre, Paul (ed.), The New Cambridge Medieval History, i: c. 500-700, Cambridge, Cambridge University Press, p. 56-92.
Isla, Amancio (1990): «Las relaciones entre el reino visigodo y los reyes merovingios a finales del siglo VI», En la España medieval, I3, p. II-32 (https://revistas.ucm.es/index.php/ELEM/article/view/ELEM9o9orroorIA/23759). James, Edward (2009): Europe's Barbarians, AD 200-600, Harlow, Pearson. Jiménez Garnica, Ana Ma. (20I0): Nuevas 'gentes', nuevo Imperio: los godos y Occidente en el siglo V, Madrid, Universidad Nacional de Educación a Distancia.

JimÉnez SÁncheZ, JuAn Antonio (2013): «El reinado de Gesaleico según la Pseudo Chronica Caesaraugustana", en Benoist, Stéphane, Hoët-van Cauwenberghe, Christine (dirs.), La vie des autres. Histoire, prosopographie, biographie dans l'Empire Romain, Villeneuve d'Ascq, Éditions du Septentrion, p. 219-230.

Kulikowski, Michael (2004): Late Roman Spain and Its Cities, BaltimoreLondon, The John Hopkins University Press.

Lizzi Testa, Rita (2016): «Bishops, Ecclesiastical Institutions, and the Ostrogothic Regime», en Arnold, Jonathan J., Bjornlie, M. Shane, Sessa, Kristina (eds.), A Companion to Ostrogothic Italy, Leiden-Boston, Brill, p. 45I-479.

Martin, CÉLIne (1998): «Las cartas de Montano y la autonomía episcopal de la Hispania septentrional en el siglo VI», Hispania Antiqua, 22, p. 403-423. Mathisen, Ralph W. (1992): Roman Aristocratis in Barbarian Gaul: Strategies for Survival in an Age of Transition, Austin, University of Texas Press.

MCKitTerick, Rosamond (1995): «Introduction: Sources and Interpretation", en McKitterick, Rosamond (ed.), The New Cambridge Medieval History, vol. II, c. 700-c.9oo, Cambridge, Cambridge University Press, p. I-I7. Moorhead, John (1995): «Gregory of Tours on the Arian Kingdoms», Studi Medievali, Serie terza, 36/2, p. 903-915.

O’Donnel, James J. (198I): «Liberius the Patrician», Traditio, 37, p. 3I-72 (https://www.cambridge.org/core/journals/traditio/article/liberius-thepatrician/D6322 $\left.\mathrm{A}_{52} \mathrm{E}_{7} \mathrm{~F}_{3} \mathrm{AA} 5 \mathrm{Ao}_{5} \mathrm{ICB} 89 \mathrm{C}_{22} \mathrm{D} 5 \mathrm{~B}_{7} \mathrm{E}\right)$.

OrLANDis, José (I962): «La sucesión al trono en la monarquía visigoda», en Estudios visigóticos, III. El poder real y la sucesión al trono en la monarquía visigoda, Roma-Madrid, CSIC, p. 57-IO2.

Orlandis, José (1977): Historia de España: La España visigótica, Madrid, Gredos.

OrLANDis, José (1980): «La ambigua jurisdicción toledana», Cuadernos de Historia de España, 63-64, p. 7-II.

Orlandis, José (2003): Historia del reino visigodo español. Los acontecimientos, las instituciones, la sociedad, los protagonistas, Madrid, Ediciones Rialp.

OzóG, Monika (2016): 'Inter duas potestastes': The Religious Policy of Theoderic the Great, Frankfurt am Main, Peter Lang.

Pérez SÁnchez, Dionisio (1989): El ejército en la sociedad visigoda, Salamanca, Ediciones Universidad de Salamanca.

Petersen, Leif I. R. (2013): Siege Warfare and Military Organization in the Successor States (400-800): Byzantium, the West and Islam, Leiden, Brill.

Pina LuCIndo, Juan José (2013): «Cartas de Montano y nómina de asistentes a los concilios toledanos ene 1 Archivo diocesano de Zaragoza», Aragonia Sacra: revista de investigación, 22, p. 249-26o.

Pohl, Walter, Dörler, Philipp (2015): «Isidore and the gens Gothorum», Antiquité Tardive, 23, p. 133-I42 (https://www.brepolsonline.net/doi/ abs/Io.I484/J.AT.5.I09374?.journal Code=at).

Poveda Arias, Pablo (2019): «La diócesis episcopal en la Hispania visigoda: concepción, construcción y disputas por su territorion, Hispania Sacra, 7I/I43, p. 9-24. (https://doi.org/IO.3989/hs.2019.00I).

SAitTa, Biagio (1994): La civilitas di Teoderico: rigore ammnistrativo, 'tolleranza' religiosa e recupero dell'antico nell'Italia ostrogota, Roma, L'Erma. 
Sardella, Teresa (1996): Società, Chiesa e Stato nell' età di Teoderico: papa Simmaco e lo scisma laurenziano, Soveria Mannelli, Rubbetino.

SARti, Laury (20I3): Perceiving War and the Military in Early Christian Gaul (ca. 400-700 A. D.), Leiden, Brill.

Schaferdiek, Knut (1967): Die Kirche in der Reichen der Westgoten und Suewen bis zur Errichtung der westgotischen katholischen Staatskirche, Berlin, De Gruyter.

Sсhмidt, Hans-Joachim (2003): «Le roi et son trésor. Fonction de la puissance royale pendant le haut Moyen Âge ", Thesis. Cahier d'histoire des collections, 2, p. 5-25.

SCHWARCZ, ANDrEAS (2002): «Relations between Ostrogoths and Visigoths in the Fifth and Sixth Centuries and the Question of Visigothic Settlement in Aquitaine and Spain», en Pohl, Walter, Diesenberger, Maximilian (eds.), Integration und Herrschaft. Ethnische Identiätent und soziale Organisation im Frühmittelalter, Wien, Verlag der Österreichische Akademie der Wissenschaften, p. 217-226.

Sessa, Kristina (2016): «The Roman Church and its Bishops», en Arnold, Jonathan J., Bjornlie, M. Shane, Sessa, Kristina (eds.), A Companion to Ostrogothic Italy, Leiden-Boston, Brill, p. 425-450.

Thompson, Edward A. (20II): Los godos en España, Madrid, Alianza Editorial (ed. orig. 1969, The Goths in Spain, Oxford, Clarendon Press).

Ubric Rabaneda, Purificación (2004): La Iglesia en la Hispania del siglo $V$, Granada, Ediciones Universidad de Granda.

Ubric Rabaneda, Purificación (20I5): «Forjando una alianza para la dominación. Obispos y bárbaros en el Occidente tardoantiguo», en Fernández Ubiña, José, Quiroga Puertas, Alberto J., Ubric Rabaneda, Purificación (coords.), La Iglesia como sistema de dominación en la Antigüedad Tardía, Granada, Ediciones Universidad de Granada, p. I5I-I68.

VALVERde Castro, Ma. Rosario (2002): «La derrota visigoda en la batalla de Vouillé: factores internos», en Scripta antiqua: in honorem Ángel Montenegro Duque et José María Blázquez Martínez, Valladolid, S. Crespo, p. $803-8 \mathrm{I} 3$.

VAN DAM, Raymond (1985): Leadership and Community in Late Antique Gaul, Berkeley, University of California Press.

VeLÁzquez, Isabel (2000): «Zonas y problemas eclesiásticos durante la época de la presencia bizantina en Hispania (una reflexión sobre los textos", en Gurt, Josep Ma. (ed.), VReunió d'Arqueologia Cristiana Hispànica, Barcelona, Institut d'Estudis Catalans, p. 585-60o.

VeLÁzquez, IsABEL, Ripoll, Gisela (2000): «Toletum, la construcción de una urbs regia», en Ripoll López, Gisela, Gurt, Josep Ma. (eds.), Sedes regiae (ann. 400-800), Barcelona, Reial Acadèmia de Bones Lletres, 2000, p. 521-578.

Wolfram, Herwig (1988): History of the Goths, Berkeley-Los Angeles, University of California Press (ed. orig. 1979, Geschichte der Goten, München, Oscar Beck).

Wood, IAN (2003): «Gregorio de Tours y Clodoveo», en Little, Lester K., Rosenwein, Barbara H. (eds.), La Edad Media a debate, Madrid, Akal, p. I25I53 (ed. orig. 1985, Revue belge de Philologie et d'Histoire, 63/2, p. 249-272).

Wood, Jamie (2012A): The Politics of Identity in Visigothic Spain: Religion and Power in the Histories of Isidore of Seville, Leiden, Brill.

Wood, JAMIE (20I2B): «Playing the Fame Game: Bibliography, Celebrity, and Primacy in Late Antique Spain", Journal of Early Christian Studies, 20/4, p. 6I3-640 (https://muse.jhu.edu/article/49236I). 
